\title{
Varietal identification in olive tree (Olea europaea L.) by morphological and biometric characterization of fruits and stones of Algerian cultivars
}

\author{
K. Titouh ${ }^{1}$, F. Bradaï ${ }^{2}$, A. Allam ${ }^{3}$, H. Madani ${ }^{3}$, B. Taleb ${ }^{2}$ and M.Z. Aït Meziane ${ }^{4}$ \\ ${ }^{1}$ National Institute of Agronomic Research of Algeria (INRAA), Center of Baraki, Algiers, Algeria \\ ${ }^{2}$ University Center Morsli Abdallah of Tipaza, Algeria \\ ${ }^{3}$ National Institute of Agronomic Research of Algeria (INRAA), Sidi Mahdi Station, Touggourt-Ouargla, Algeria \\ ${ }^{4}$ National Institute of Agronomic Research of Algeria (INRAA), Oued Ghir Station, Béjaïa, Algeria
}

\section{Summary}

Varietal identification is a key step for good management of genetic diversity and better exploitation of the existing potential. In olive tree, despite the development of the molecular and biochemical tools; morphological characterization remains used for varietal distinction and the identification of new genotypes. Several studies have shown the acceptable stability of the biometric characteristics of the olive and the stone allowing a good discrimination between varieties. So, the present study aims to recognize in a cost-efficient way the varieties to which belong olive trees in a productive orchard based only on the qualitative and quantitative characteristics of their fruits and extracted stones in order to a better valorization of this diversity. Forty mature fruits were sampled from each olive tree. After fruit's characterization, stones were extracted and described. Twenty morphological characters (10 for fruits and $\mathbf{1 0}$ for stones) were retained in this work. Control fruit samples of each one of the Algerian olive varieties were recovered from a living olive collection as reference. The analysis of the results showed the existence of about ten different phenotypes of which 5 have been recognized perfectly belonging to reference cultivars only using morphological characters of their fruits and stones. The other groups of trees, having shown characteristics close to those of certain known cultivars, remain unidentified. The approach followed confirmed the usefulness of morphological descriptors of olives and stones and their discriminating power in the recognition of olive cultivars as an economical alternative to the use of molecular markers.

Keywords

characteristics, genetic diversity, genotype, living collection, olives, orchard, variety

\section{Introduction}

The olive tree (Olea europaea L. ssp. europaea) is one of the characteristic species of the Mediterranean basin. A diploid species belonging to the Oleaceae family, the olive tree includes wild (var. sylvestris) and cultivated varieties (var. sativa) (Green, 2002). Grown on around 12 million hectares and with an average annual production of more than 3 million tonnes of olive oil, olive tree is one of the world's major

\section{Significance of this study}

What is already known on this subject?

- The morphological description of certain plant organs particularly fruits and seeds remains used for varietal identification and distinction.

What are the new findings?

- Recognition of the olive varieties in a productive orchard is possibly based only on the morphological and biometric characteristics of their fruits and stones.

What is the expected impact on horticulture?

- Varietal identification is a key step for good management of genetic diversity and better exploitation of the existing potential.

oilseed crops (FAOSTAT, 2017; IOC, 2018). In Algeria, olive growing occupies approximately 470 thousand hectares and produces around 700 thousand tons of olives (MARDF, 2017).

The olive tree includes an important genetic diversity exceeding 2,600 cultivars (Cvs.) identified over the world (FAO, 2010) which have been selected mainly based on the size of their fruit, the proportion occupied by the pulp and the oil content. However, this number of cultivars is probably underestimated due to lack of information on local genotypes generally in the minority (El Bakkali et al., 2019). To overcome these problems, morphological traits have been formerly used for the description, distinction and classification of different olive cultivars (Ruby, 1917 in Idrissi and Ouazzani, 2006) as well as to describe the developed or found genotypes. Thus, a method of primary morphological characterization has been adopted by the International Olive Council (IOC) for a better agronomic valorization and knowledge of olive genetic resources (Barranco, 1994; IOC, 1997). Since then, several identification works in many countries demonstrated the great utility of these markers in resolving several cases of homonymy and synonymy (Caballero and Del Rio, 1999). In Algeria, Hauville (1953) suggested the existence of more than 150 of olive varieties, while Mendil and Sebai (2006), using the descriptor considered by the IOC, identified and characterized only 36 cultivars through the country whose appellations are often in relation with the region of culture or dissemination, their practical use or 
characters specific to their fruit. The most common varieties are 'Chemlal' for oil extraction and 'Sigoise' as table olive. However, several researches mention other names of local varieties confirming a large diversity because of the lack of information on restricted local varieties (Dominguez-Garcia et al., 2012; Abdessemed et al., 2015).

To supplement the contribution of the morphological descriptors, other types of markers, biochemical and enzymatic, less influenced by the environment, have been developed (Pontikis et al., 1980). Subsequently, the molecular tool (RAPD, SSR, ISSR, SNP, etc.) has contributed significantly to the varietal identification as well as the study of inter- and intra-specific genetic relationships within olive tree (Trujillo et al., 2014). Nevertheless, the importance of morphological description remains essential in the classification, recognition and authentication of olive cultivars in field surveys and living collections and has aroused particular interest in recent years due to the strong discrimination of certain morphological characteristics, particularly those of fruits and stones, and the positive correlation showed with the other types of markers, particularly molecular ones (El Bakkali et al., 2019) as well as their high stability and weak influence by external conditions compared to those of other organs such as leaves or inflorescences (Idrissi and Ouazzani, 2006).

The objective of our study is firstly, to verify the possibility to recognize the cultivars to which belong olive trees planted ignoring their varieties in south of Algeria based only on the morphological characters of their fruits and stones through a statistical analysis and referring to a living olive collection to suggest, secondly, a suitable and economical as well as reassuring method for the determination of common cultivars based on the discriminating power and acceptable stability of such markers without using molecular tools requiring some control. Consequently, knowledge of orchard varieties is a prerequisite for an appropriate cultural management allowing a good ex-situ conservation of genetic resources as well as a better valorization and exploitation of the existing potentials (industrial use and processing) in addition to launching of other research activities (breeding programs, varietal behavior, biological studies, etc.).

\section{Materials and methods}

\section{Plant material}

The plant material consisted of the fruits sampled from 192 productive olive trees among 210 planted ignoring their varieties within the experimental station of the National Institute of Agronomic Research of Algeria (INRAA) located at Sidi Mahdi-Touggourt in the department of Ouargla located at $660 \mathrm{~km}$ southeast of Algiers on an altitude of about $72 \mathrm{~m}$. The orchard trees of eight years old were maintained under irrigation.

TABLE 1. Contribution of the morphological characters (quantitative and qualitative) of the fruit and the stone used for the identification of olive varieties in the total inertia explained by the Multiple Correspondence Analysis (MCA).

\begin{tabular}{|c|c|c|c|c|c|c|}
\hline $\begin{array}{l}\text { Described } \\
\text { part }\end{array}$ & Character & Categories & Abbreviation & $\begin{array}{l}\text { Contribution in } \\
\text { total inertia (\%) }\end{array}$ & $\begin{array}{l}\text { Classification of } \\
\text { the discriminating } \\
\text { power }\end{array}$ & $\begin{array}{c}\text { Contribution in } \\
\text { the varietal } \\
\text { identification (\%) }\end{array}$ \\
\hline \multirow[t]{10}{*}{ Fruit } & Weight & 4 (Low, Medium, High, Very high) & FW & 4.5 & 12 & 50.8 \\
\hline & Shape a & 3 (Spherical, Ovoid, Elongated) & FS & 7.8 & 2 & \\
\hline & Symmetry in A position ${ }^{b}$ & $\begin{array}{l}3 \text { (Asymmetric, Slightly asymmetric, } \\
\text { Symmetric) }\end{array}$ & FSy & 4.4 & 13 & \\
\hline & $\begin{array}{l}\text { Position of maximal } \\
\text { transversal diameter }\end{array}$ & $\begin{array}{l}3 \text { (Towards base, Central, Towards } \\
\text { apex) }\end{array}$ & FD & 5.9 & 6 & \\
\hline & Apex & 2 (Rounded, Pointed) & FA & 5.7 & 9 & \\
\hline & Base & 2 (Rounded, Truncate) & FB & 4.2 & 14 & \\
\hline & Number of lenticels ${ }^{c}$ & 2 (Few, Many) & FLn & 3.6 & 15 & \\
\hline & Dimension of lenticels ${ }^{c}$ & 2 (Small, Large) & FLd & 5.8 & 7 & \\
\hline & Beginning of ripening & $\begin{array}{l}3 \text { (From the base, Uniformly, From } \\
\text { the apex) }\end{array}$ & FR & 5.7 & 10 & \\
\hline & Nipple & 3 (Absent, Tenuous, Obvious) & FN & 3.1 & 18 & \\
\hline \multirow[t]{10}{*}{ Stone } & Weight & 4 (Low, Medium, High, Very high) & SW & 7.3 & 3 & 49.2 \\
\hline & Shape a & 4 (Spherical, Ovoid, Elliptic, Elongated) & SS & 6.2 & 4 & \\
\hline & Symmetry in A position ${ }^{b}$ & $\begin{array}{l}3 \text { (Asymmetric, Slightly asymmetric, } \\
\text { Symmetric) }\end{array}$ & SSy-A & 5.0 & 11 & \\
\hline & Apex & 2 (Rounded, Pointed) & SA & 5.7 & 8 & \\
\hline & Base & 3 (Rounded, Pointed, Truncate) & SB & 3.3 & 17 & \\
\hline & Symmetry in B position ${ }^{b}$ & $\begin{array}{l}3 \text { (Asymmetric, Slightly asymmetric, } \\
\text { Symmetric) }\end{array}$ & SSy-B & 8.9 & 1 & \\
\hline & $\begin{array}{l}\text { Position of maximal } \\
\text { transversal diameter }\end{array}$ & $\begin{array}{l}3 \text { (Towards base, Central, Towards } \\
\text { apex) }\end{array}$ & SD & 6.2 & 5 & \\
\hline & Surface & 3 (Smooth, Rugose, Scabrous) & SSu & 3.4 & 16 & \\
\hline & Number of grooves & 3 (Low, Medium, High) & SG & 3.1 & 19 & \\
\hline & Mucron & 2 (Present, Absent) & SMu & 1 & 1 & \\
\hline
\end{tabular}

a: The shape is deduced from the ratio between the length $(L)$ and width $(W)$ of the fruit or stone. $\mathrm{b}:$ The position $A$ is where the fruit or stone presents its maximum asymmetry when it is kept between the thumb and the forefinger while the position $B$ is that resulting from the rotation of $90^{\circ}$ from the position $\mathrm{A}$ in the opposite direction to the needles of the watch. c: The number and size of lenticels are observed on green fruits. 


\section{Morphological and biometric characterization of fruits and stones}

A sample of 40 mature fruits was recovered from the middle part of each olive tree as recommended by Idrissi and Ouazzani (2006), particularly the south-facing one. Samples were kept at $4^{\circ} \mathrm{C}$ and used progressively for the description. Twenty morphological characters (10 for fruits and 10 for stones), among the characters of the descriptor used for the primary characterization of olive varieties (IOC, 1997) were retained for this study. Each character presents between 2 and 4 categories (Table 1). The weight of each fruit or stone was obtained using a precision balance while the length (L) and width $(\mathrm{W})$ of the samples were performed with a caliper. The shape of the fruit or stone was deduced from the ratio $(\mathrm{L} / \mathrm{W})$ between their length and width. The number of grooves was observed under a binocular loupe. Subsequently, the ratio "pulp/fruit" indicating the proportion of the pulp with respect to the whole fruit in addition to "pulp thickness" were calculated by the following formulas:

$$
\begin{aligned}
& \text { Pulp/Fruit ratio }(\%)=\frac{(\text { Fruit weight }- \text { Stone weight })}{\text { Fruit weight }} \times 100 \\
& \text { Pulp thickness }(\mathrm{cm})=\frac{(\text { Fruit diameter }- \text { Stone diameter })}{2}
\end{aligned}
$$

\section{Varieties identification}

To recognize existing varieties within the studied orchard; control fruits samples of each one of the Algerian olive varieties were recovered from the national olive collection at the INRAA experimental station at Oued Ghir-Béjaïa (Hamdi and Khanouche, 2007) which was created from the national olive collection of cultivars already identified and described by the Technical Institute of Fruit Arboriculture and Vine (ITAFV) in 2006 (Mendil and Sebai, 2006) and characterized by some recent molecular studies (Abdessemed et al., 2015; Haddad et al., 2020). As for the studied olive trees, a sample of 40 fruits was recovered from each variety and characterized by the same characters previously considered (Table 1).

\section{Statistical analysis of the data}

Quantitative traits of the fruits and stones (weight, shape, and number of grooves) were treated with Principal Component Analysis (PCA), while qualitative traits were processed by Factorial Correspondence Analysis (FCA). Following the transformation of quantitative characters into classes according to Barranco (1994) and IOC (1997), the whole of multi-trait phenotypes resulting from the combination of the categories of the 20 characters used was presented in form of a complete disjunctive table (CDT) and subjected to a Multiple Correspondence Analysis (MCA) as recommended by Idrissi and Ouazzani (2006) and later followed by an Ascending Hierarchical Classification (AHC) to aggregate similar olive trees. The links between the different parameters were determined by their correlation coefficients and the significance was verified with the Student's test.

Thereafter, in order to recognize the varieties to which each group of olive trees belongs, the results obtained from the description of the reference varieties have been integrated into the database of the studied olive trees and a PCA was applied on the quantitative data, FCA to the qualitative data and an MCA on all the characters represented in classes or categories presented in CDT. The Ascending Hierarchical Classification was achieved with the Jaccard similarity index with an aggregation method based on the average link between individuals. This classification was carried out in order to position the studied olive trees with the varieties used as reference according to their morphological similarity levels. Once the groups were identified, one-way analysis of variance of the measured parameters was performed, followed by a multiple comparison using the least significant difference (LSD) test. Values followed by the same letters were not significantly different at a level of $5 \%$. The software used for all analyzes was XLSTAT (v. 2016.02.27444).

\section{Results}

The morphological description of the fruits and stones of the studied olive trees revealed an important phenotypic diversity. Among the 57 possible categories of the 20 characters selected (Table 1), 45 were observed in the studied samples. So, on all the samples of fruits analyzed; the spherical shape, the perfect symmetry, the presence of the nipple, the position of the maximal diameter directed towards the apex as well as a beginning of ripening from the base were not observed. Fruits of the majority of samples were low weight $(<2 \mathrm{~g})$ and the most common form was elongated ( $\mathrm{L} / \mathrm{W}>1.45)$, more asymmetrical with a central maximal diameter and generally have a pointed apex, rounded base and uniform ripening.

TABLE 2. Number of olive trees per group obtained by the Ascending Hierarchical Classification (AHC) and biometric

\begin{tabular}{|c|c|c|c|c|c|c|c|c|c|}
\hline \multirow[b]{2}{*}{$\begin{array}{l}\text { AHC } \\
\text { Groups }\end{array}$} & \multicolumn{2}{|c|}{ Olive trees } & \multicolumn{2}{|c|}{ Fruits } & \multicolumn{2}{|c|}{ Stones } & \multirow[b]{2}{*}{$\begin{array}{l}\text { Pulp/fruit } \\
\text { ratio } \\
(\%)\end{array}$} & \multirow[b]{2}{*}{$\begin{array}{l}\text { Pulp } \\
\text { thickness } \\
\text { (cm) }\end{array}$} & \multirow[b]{2}{*}{$\begin{array}{l}\text { Identified } \\
\text { cultivar }\end{array}$} \\
\hline & $\begin{array}{c}\text { Number } \\
\text { (/192 trees) }\end{array}$ & $\begin{array}{c}\% \text { of } \\
\text { studied } \\
\text { trees }\end{array}$ & $\begin{array}{l}\text { Weight } \\
\text { (g) }\end{array}$ & $\begin{array}{l}\text { Shape } \\
\text { (L/W) }\end{array}$ & $\begin{array}{l}\text { Weight } \\
\text { (g) }\end{array}$ & $\begin{array}{l}\text { Shape } \\
\text { (L/W) }\end{array}$ & & & \\
\hline Cv1 & 108 & 56.3 & $1.61 \pm 0.249$ & $1.48 \pm 0.03^{d}$ & $0.41 \pm 0.04$ & $1.99 \pm 0.07^{d}$ & $73.7 \pm 0.1 \mathrm{e}$ & $0.23 \pm 0.04^{\mathrm{h}}$ & Chemlal \\
\hline Cv2 & 64 & 33.3 & $2.62 \pm 0.33^{d}$ & $1.38 \pm 0.04 \mathrm{e}$ & $0.55 \pm 0.07 c$ & $1.90 \pm 0.07^{e}$ & $78.6 \pm 0.1^{c}$ & $0.32 \pm 0.04 \mathrm{e}$ & Sigoise \\
\hline Cv3 & 5 & 2.6 & $3.94 \pm 0.06^{b}$ & $1.22 \pm 0.03^{h}$ & $0.74 \pm 0.02^{b}$ & $1.54 \pm 0.08^{g}$ & $80.9 \pm 0.4^{b}$ & $0.43 \pm 0.02^{b}$ & Longue de Miliana \\
\hline Cv4 & 3 & 1.6 & $1.33 \pm 0.06^{h}$ & $1.49 \pm 0.02^{c}$ & $0.31 \pm 0.00^{9}$ & $2.34 \pm 0.13^{a}$ & $76.7 \pm 0.5^{d}$ & $0.27 \pm 0.01^{f}$ & Abani \\
\hline Cv5 & 1 & 0.5 & $7.88 \pm 1.95^{\mathrm{a}}$ & $1.38 \pm 0.12^{\mathrm{e}}$ & $1.16 \pm 0.24^{a}$ & $2.11 \pm 0.21^{\mathrm{bc}}$ & $84.9 \pm 0.8^{\mathrm{a}}$ & $0.69 \pm 0.1^{\mathrm{a}}$ & Aguenaou \\
\hline Cv6 & 5 & 2.6 & $1.80 \pm 0.18^{f}$ & $1.55 \pm 0.05^{b}$ & $0.52 \pm 0.13^{d}$ & $2.09 \pm 0.08^{c}$ & $71.7 \pm 0.4^{f}$ & $0.25 \pm 0.05^{9}$ & Unidentified \\
\hline Cv7 & 3 & 1.6 & $2.14 \pm 0.17 \mathrm{e}$ & $1.38 \pm 0.03^{\mathrm{e}}$ & $0.33 \pm 0.03^{f}$ & $2.13 \pm 0.06^{b}$ & $84.4 \pm 0.5^{\mathrm{a}}$ & $0.35 \pm 0.07^{d}$ & Unidentified \\
\hline Cv8 & 1 & 0.5 & $0.55 \pm 0.05$ & $1.85 \pm 0.1^{\mathrm{a}}$ & $0.19 \pm 0.02^{\mathrm{h}}$ & $2.32 \pm 0.15^{\mathrm{a}}$ & $65.6 \pm 0.8^{9}$ & $0.12 \pm 0.01^{i}$ & Unidentified \\
\hline Cv9 & 1 & 0.5 & $2.76 \pm 0.26^{c}$ & $1.25 \pm 0.06^{9}$ & $0.45 \pm 0.06^{d}$ & $1.94 \pm 0.19^{e}$ & $83.5 \pm 0.8^{\mathrm{a}}$ & $0.41 \pm 0.04^{c}$ & Unidentified \\
\hline Cv10 & 1 & 0.5 & $1.33 \pm 0.17^{\mathrm{h}}$ & $1.33 \pm 0.05^{f}$ & $0.29 \pm 0.04 \mathrm{~g}$ & $1.77 \pm 0.09 f$ & $77.9 \pm 0.8^{\mathrm{cd}}$ & $0.26 \pm 0.04^{\mathrm{fg}}$ & Unidentified \\
\hline
\end{tabular}
parameters of their fruits, stones, pulp and the corresponding cultivars identified*.

* The different letters indicate a significant difference at a level of $5 \%$. 


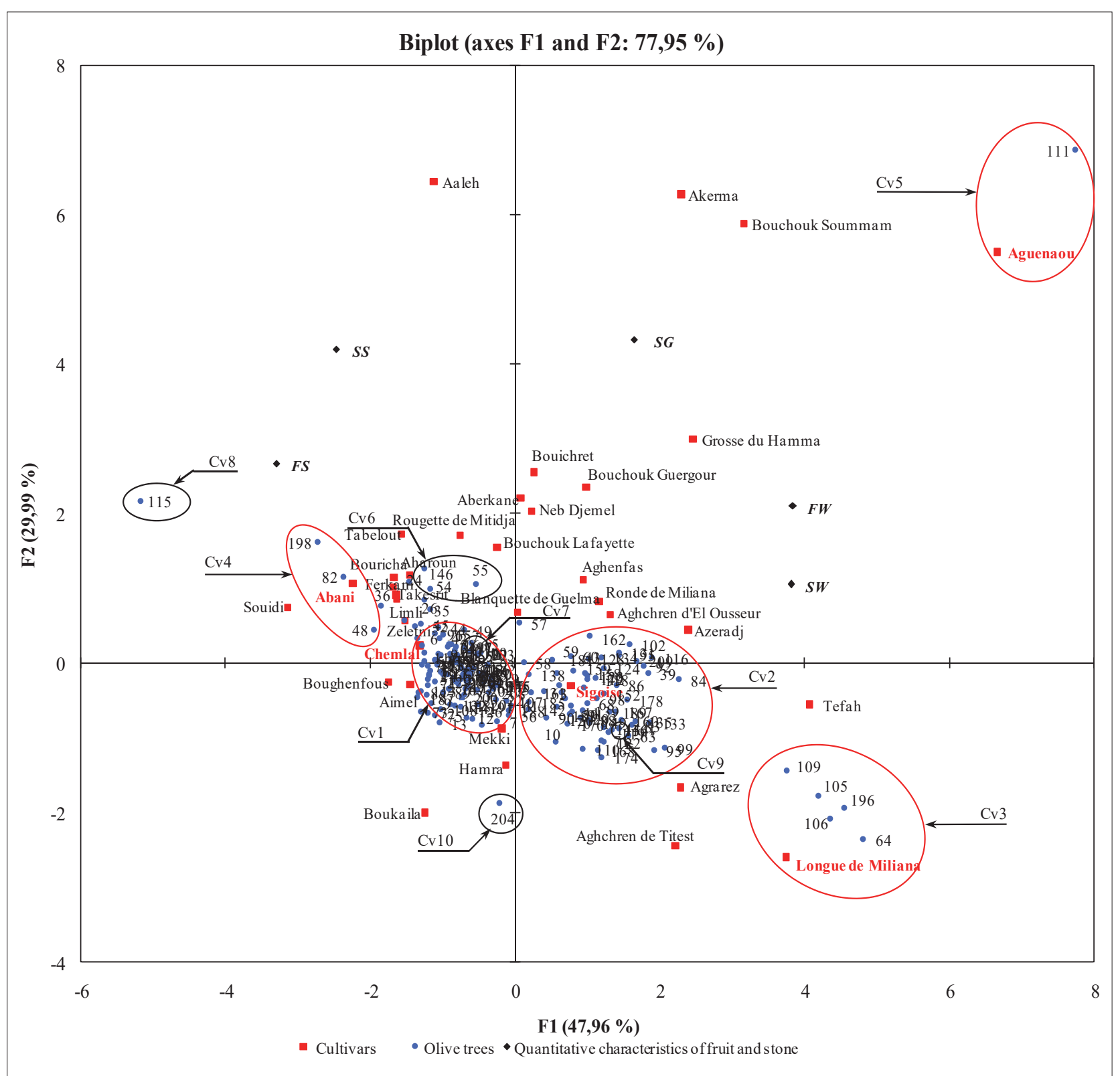

FIGURE 1. Representation of the studied olive trees and the reference cultivars on the first two axes of the Principal Component Analysis (PCA).

Lenticels were numerous and small. Likewise, the spherical shape, the absolute symmetry as well as the absence of the mucron were not observed in stones presenting a medium to high weight $(0,3$ to $0,7 \mathrm{~g})$ and were more elliptical shape ( $\mathrm{L} / \mathrm{W}$ between 1,8 and 2,2 ), slightly asymmetric with a pointed apex, rounded base and a centered maximal diameter. The surface of the stones was generally smooth with a medium number of grooves (Table 2; Figure 4). The presence of mucron in the endocarp was homogeneous even in the cultivars used as reference. As a result, this character was placed as an inactive variable and discarded during data analysis.

Principal component analysis (PCA) of quantitative traits showed that the first two axes explained together $78 \%$ of the variation observed in the studied orchard (Figure 1). The first axis, accounting alone $47.96 \%$ of the information, was positively correlated with the weight and shape of the fruit in addition to the weight of the stone, while the second component defined by the shape of the stone and the number of grooves, explained $30 \%$ of the variability. In addition, significant positive correlations were observed between the weight and shape of the fruit with the same parameters measured on the extracted stone. Regarding the contribution of quantitative characteristics to total inertia, the analysis showed that the parameters of the fruit contributed more than those of the stone in the discrimination of tree with $52.3 \%$ and $47.7 \%$, respectively. The weight of the fruit and the stone were the most discriminating quantitative characters with 30.1 and $29.7 \%$, respectively, of the total inertia, followed by the shape of the fruit $(22.2 \%)$, shape of the stone $(12.5 \%)$ while the number of grooves contributed less than $6 \%$. The projection of the individuals on the two axes of the PCA (Figure 1) allowed a clear distinction of eight groups of olive trees, five of which perfectly included well-identified reference cultivars: 'Abani', 'Aguenaou', 'Chemlal', 'Longue de Miliana' and 'Sigoise'. However, three other groups of olive trees $(115,204$ and the group of olive trees: 54-55-146) differed significantly from all cultivars used as reference for identification.

Factorial correspondence analysis (FCA) of qualitative characteristics showed that nearly $67 \%$ of the information 


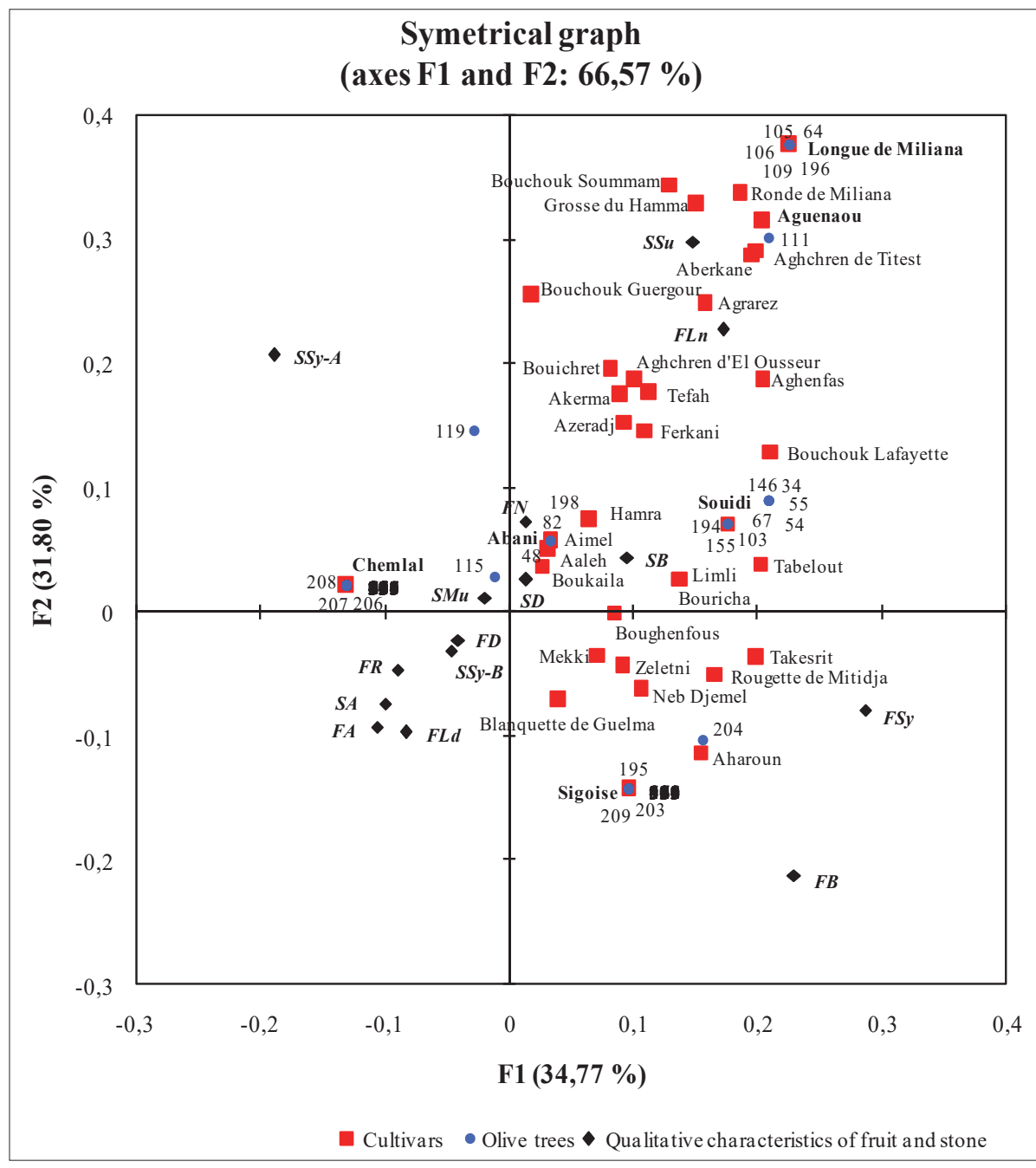

FIGURE 2. Representation of the studied olive trees and the reference cultivars on the first two axes of the Factorial Correspondence Analysis (FCA).

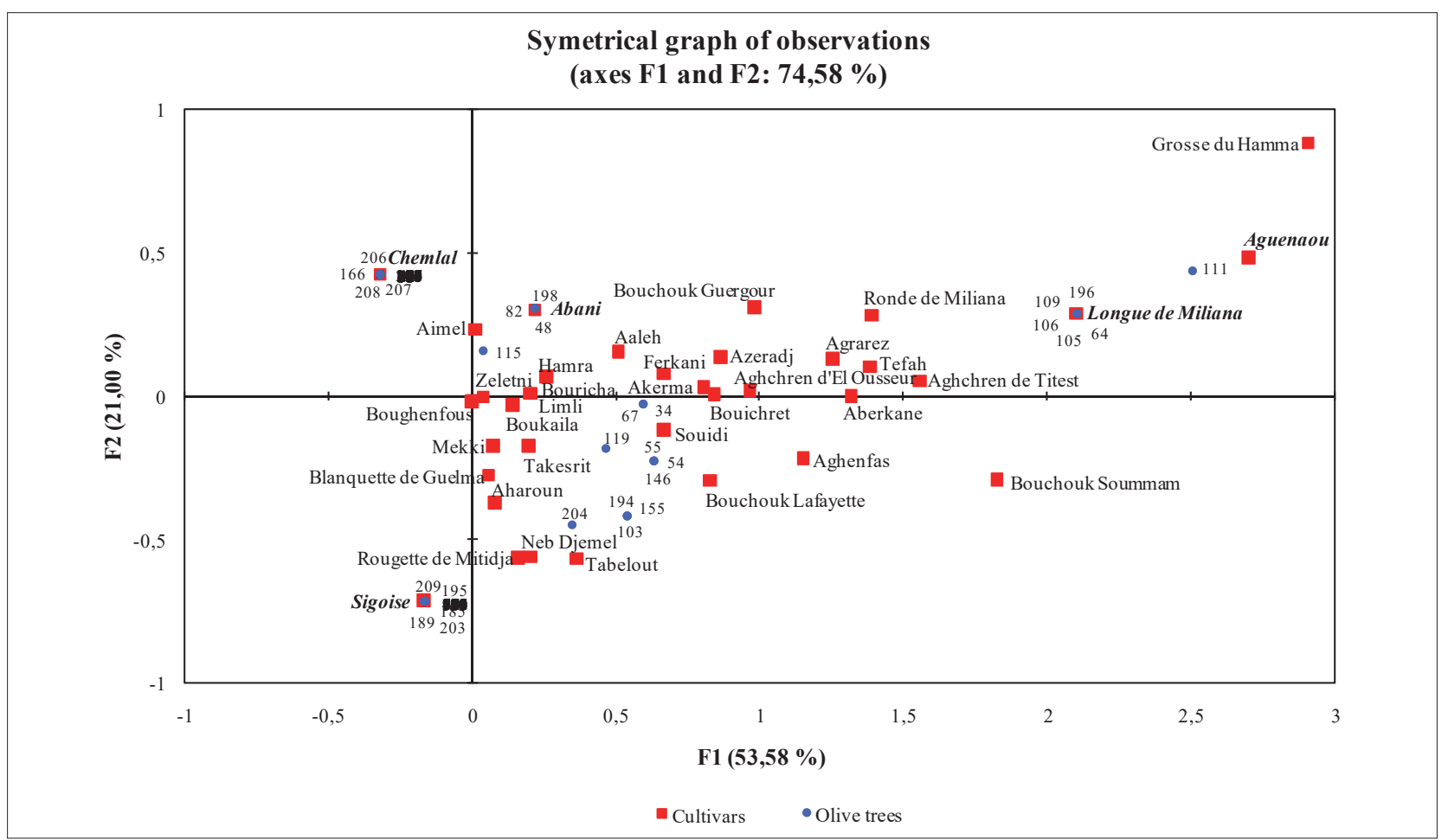

FiguRE 3. Representation of the studied olive trees and the reference cultivars on the first two axes of the Multiple Correspondence Analysis (MCA) of the resulting profiles from the combination of the quantitative and qualitative characters represented in classes. 


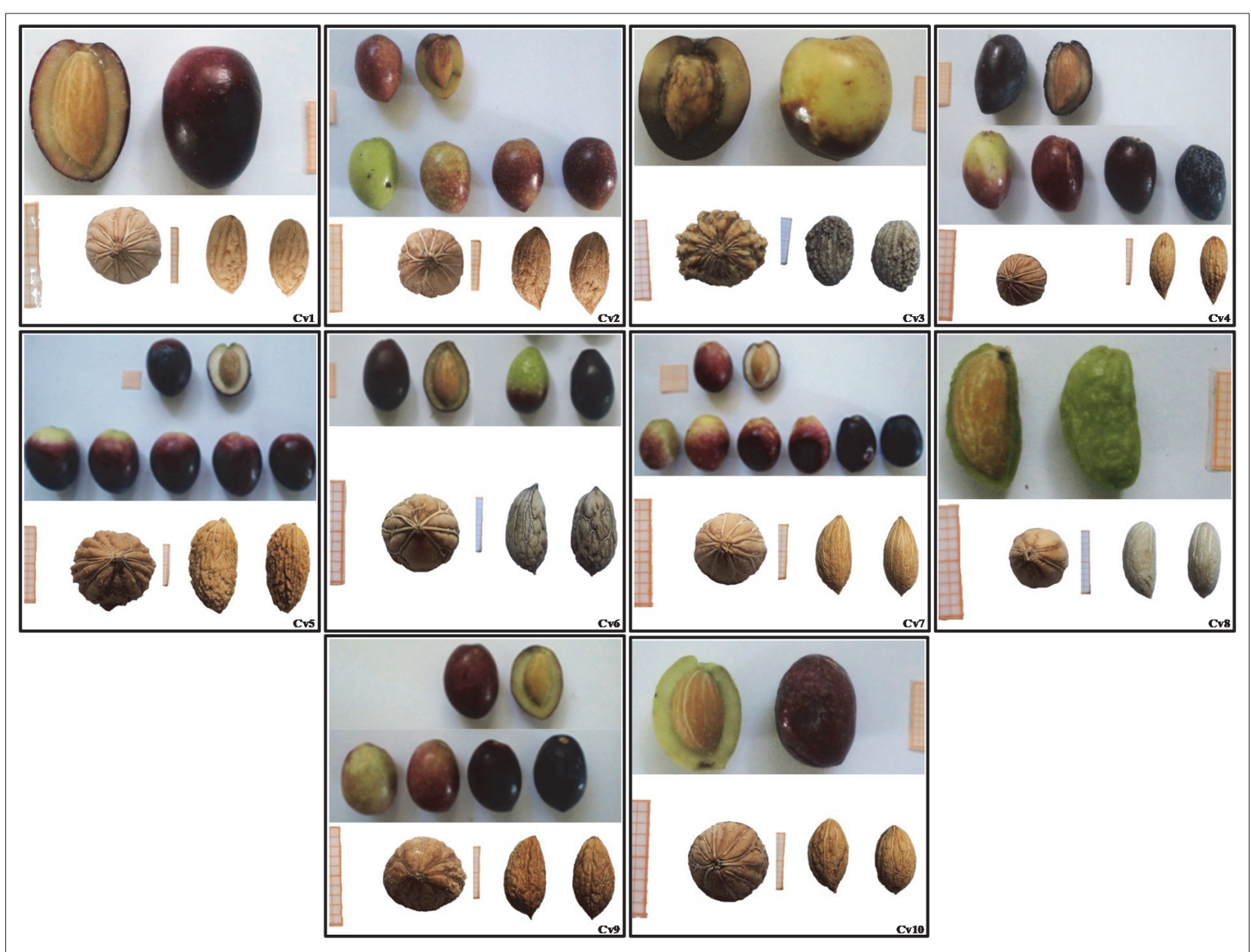

FIGURE 4. The fruits (with different stages of maturity) and stones (top view, position A and B) of the different olive cultivars identified on the studied orchard (Scale: $1 \mathrm{~cm}$ millimeter paper).

provided by these characters was summarized in the first two axes (Figure 2). The first axis accounted about 35\% of the diversity while the second included more than $31 \%$ of the information. The FCA allowed to group olive trees with the same qualitative characteristics and to gather them perfectly with the corresponding reference cultivars. In addition, the qualitative characteristics of the fruit contributed to more than $50 \%$ in the total inertia and consequently in the discrimination between the various olive trees studied. Thus, the projection of the olive trees studied on the two axes of the FCA showed the existence of 10 groups of olive trees, five of which have profiles of characteristics identical to those of the reference cultivars: 'Abani', 'Chemlal', 'Longue de Miliana', 'Sigoise' as well as 'Souidi'. The other five groups of olive trees $(111,115,119,204$ in addition to the group comprising the olive trees 34-54-55-67-146) did not join any cultivar used as reference for varietal recognition.

Multiple correspondence analysis (MCA) of the multitrait phenotypes generated by the combination of the 19 character quantitative and qualitative categories allowed to distinguish 11 groups of olive trees among which four were clearly positioned on cultivars of reference: 'Abani', 'Chemlal', 'Longue de Miliana' and 'Sigoise', while the seven other groups of olive trees $(111,115,119,204,34-67,54-55-146$ as well as the olive trees 103-155-194) remained close to certain reference cultivars (Figure 3). As for the PCA and FCA, the characteristics of the fruit contributed slightly more than those of the stone with $50.8 \%$ and $49.2 \%$ respective- ly. This contribution varied from 3.1\% (Number of grooves) to $8.9 \%$ (Symmetry of the stone in position "B"). However, in terms of the ranking of the discriminating power of the various parameters, the characters of the stone such as the weight, shape as well as the position of the maximal diameter allowed more discrimination between the olive trees than those of the fruit (Table 1).

The Ascending Hierarchical Classification carried out by the Jaccard Index on the basis of the 19 characters used for the identification of the cultivars to which belong the olive trees of the orchard allowed to identify 10 different groups of olive trees (Table 2; Figure 4):

1. Group 1: composed of 108 studied olive trees belonging to the cultivar 'Chemlal'.

2. Group 2: 64 olive trees studied belonging to the cultivar 'Sigoise'.

3. Group 3: 5 olive trees (64-105-106-109-196) belonging to the cultivar 'Longue de Miliana'.

4. Group 4: 3 olive trees (48-82-198) belonging to the cultivar 'Abani'.

5. Group 5: composed of one olive tree (111) belonging to the cultivar 'Aguenaou'.

6. Group 6: 5 olive trees (34-54-55-67-146) close to the cultivar 'Souidi'.

7. Group 7: 3 olive trees (103-155-194) close to the group 6 and the cultivar 'Souidi'.

8. Group 8: one olive tree (115) close to the cultivars 'Aimel', 'Abani' and 'Aaleh'. 
9. Group 9: one olive tree (119) which did not gather any reference cultivar.

10. Group 10: one olive tree (204) which did not match any cultivars used as reference.

Once the groups of olive trees were identified, analysis of the variance of each quantitative parameter of the fruits and stones (weight and shape) in addition to the pulp/fruit ratio as well as pulp thickness showed a significant difference between the different olive trees groups. Fruits produced by olive trees belonging to groups 5, 3 and 9 presented a high weight and thick pulp as well as heavy stones, while fruits of group 8 (olive tree 115 ) had a fine pulp $(0.12 \mathrm{~cm})$ representing less than $66 \%$ of the whole fruit (Table 2).

\section{Discussion}

Varietal identification based on the morphological description remains of great importance despite the development of molecular tools. In our study, we used the morphological characterization of olive fruits and stones to recognize the cultivars within the studied orchard. Among the five identified groups; four groups ('Chemlal', 'Sigoise', 'Abani' and 'Longue de Miliana') exhibited perfect stability of their characters (Table 2; Figure 4: Cv1 to 4) in comparison to the reference cultivars. Our results join perfectly those given by Mendil and Sebai (2006), while the fruits of the olive tree 111 ( $5^{\text {th }}$ group $)$ didn't present a nipple such as fruits of the reference cultivar 'Aguenaou' (Table 2; Figure 4: Cv5). Idrissi and Ouazzani (2006) indicated that all fruit traits were stable for five years of study, except for the presence of the nipple. Besides to its very great heterogeneity within the sample, the authors noted in some varieties a loss or reduction in nipple size from one to another year and between individuals of the same variety. Moreover, the presence of the mucron and the number of grooves on the surface of the stone had no effect on the discrimination of the varieties under study. Similarly, Emmanouilidou and Kyriacou (2018) indicated the presence of mucron in all cultivars characterized in Cyprus whereas the number of grooves was not useful to distinguish accessions from Tuscan germplasm in Italy (Cantini et al., 1999). According to Giuffrè (2017), a percentage of pulp greater than $79 \%$ indicates that the cultivar is recommended as a table olive. Our results confirm this observation because the olive trees of the groups 3 and 5 presenting a pulp/fruit ratio higher than $79 \%$ (Table 2 ) correspond respectively to the cultivars 'Long de Miliana' and 'Aguenaou' considered as table olives (Mendil and Sebai, 2006).

The fruits and stones of group 7 differed only by the quantitative parameters from those of the cultivar 'Souidi' from which fruits of the group 6 were different by the sense of the beginning of the ripening in addition to quantitative traits (Table 2; Figure 4: Cv6 and 7). According to Idrissi and Ouazzani (2006), significant decreases in the level of rainfall as an excessive dryness in certain Moroccan regions during the ripening period of local varieties lead to the formation of small fruits which did not reach their normal size leading to changes in the shape of the fruit and consequently the endocarp. Similarly, Hadiddou et al. (2013) have shown that the production performance of olive varieties differs significantly depending on the orchard management. Thus, irrigation can generate about 3.5 and $6.3 \%$ average gain in the weight of olives and stones respectively, which leads to a significant change in their shapes compared to a rainwater management. In our case, the studied orchard was irrigated whereas the orchard of reference was managed in rainwater which can be the origin of the slight increase of the weight of fruits and stones of group 7 generating, thereafter, a modification in their form although the recorded values (Table 2) were very close to limits where the cultivar 'Souidi' was classified $(\mathrm{FW}<2 \mathrm{~g}$ and $\mathrm{L} / \mathrm{W}>1.4$ for fruits and $\mathrm{SW}<0.3 \mathrm{~g}$ and $\mathrm{L} / \mathrm{W}>2.2$ for stones). Nevertheless, the growing conditions generally influence greater the measured traits, whereas the qualitative characteristics such as the sense of ripening were weakly influenced by the environment (Hannachi et al., 2017). Moreover, currently several foreign varieties of olive trees are introduced and multiplied in Algeria to which probably belong olive trees of the group 6 .

The group 8 counting one olive tree 115 is considered as a wild form because its fruits presented a very low weight $(0.55 \mathrm{~g})$ and a fine pulp $(0.12 \mathrm{~cm})$ (Table 2; Figure 4: Cv8) as well as a very low oil content (unpublished data). According to Green (2002), the wild form or the oleaster has fruits with very low weight and a thin flesh. Hannachi et al. (2008) confirmed that the discrimination between the two forms of olive tree is mainly due to the size, shape and weight of the fruit in addition to the oil content and its fatty acid composition. In our case, as the plants derived from grafting of oleaster, probably the graft was unsuccessful and the rootstock restarted.

The fruits and stones of tree 119 (group 9) and tree 204 (group 10) presented qualitative and quantitative characteristics very similar to those of 'Sigoise' (Table 2; Figure 4: Cv9 and 10). These two trees can be either different cultivars or forms of variation or adaptation of some cultivars, especially 'Sigoise'. Several authors indicated variations in the morphological characteristics of olive organs in their wild or cultivated form depending on environmental and/or crop conditions (Hadiddou et al., 2013; Hannachi et al., 2017; Dridi et al., 2018).

In this study, the MCA analysis showed that the shape of the fruit, weight and shape of the stone in addition to the position of its maximal transversal diameter as well as its symmetry contribute strongly with $36 \%$ in the distinction between varieties (Table 1 ). Our results perfectly join those of Idrissi and Ouazzani (2006), indicating a significant discriminating power of these traits in olive varietal identification. Similarly, our results of PCA also corroborate those of Laaribi et al. (2017) and Dridi et al. (2018), showing that the weight of the olive and the stone are positively correlated and were the most discriminating quantitative characteristics compared to the other biometric parameters of these parts while the number of grooves remains the least discriminating. Moreover, several studies demonstrated the superiority of the discriminative power of the characteristics of the endocarp (Barranco, 1994). In our case, the contribution of the characters of the fruit and the stone were very close with a slight superiority for those of the fruit with 50.8 and $49.2 \%$ respectively. Our results are similar to those obtained by Cantini et al. (1999) and Laaribi et al. (2017), emphasizing the importance of fruit traits for the recognition of olive cultivars. However, the use of pomological characters alone may lead to incomplete differentiation results (Hannachi et al., 2008). For this reason, integrating the characteristics of foreign cultivars in the reference database or the use of other category of markers such as enzymatic and molecular tools could contribute in the determination of the undefined cultivars.

\section{Conclusion}

Our study confirmed the great utility of the morphological description in the characterization of olive genetic re- 
sources possessing a very important phenotypic and genetic polymorphism for future improvement and enhancement programs in the Mediterranean basin. As a result, among the ten different phenotypes observed within the orchard, at least five cultivars have been recognized perfectly with the retained statistical approach while the undefined groups can be determined by expanding the database of reference cultivars with characteristics of the most common foreign varieties. In addition, the study has highlighted the usefulness of living collections as a reference for the recognition and authentication of olive cultivars, however requiring integration of more genetic resources, particularly the most cultivated varieties over the world. Furthermore, the approach followed can be easily applied to other plant species by assembling the three conditions of a good characterization with discriminating characters, large reference living collection and particularly a detailed statistical analysis of the obtained data.

\section{Acknowledgments}

This work was carried out within the framework of the institutional project "DevOlea" of INRAA. The authors wish to thank Mr Dahliz Abderrahman (Director of the INRAA Experimental Station of Sidi Mahdi-Touggourt) as well as all the personnel of the experimental station for their support and availability during the realization of this work.

\section{References}

Abdessemed, S., Muzzalupo, I., and Benbouza, H. (2015). Assessment of genetic diversity among Algerian olive (Olea europaea L.) cultivars using SSR marker. Sci. Hortic. 192, 10-20. https://doi.org/10.3389/ fpls.2019.01039.

Barranco, D. (1994). Caracterización del material vegetal en olivo. In Avances en Olivicultura (Barcelona: Fundation «La Caixa», Fruticultura profesional), p. 3-7.

Caballero, J.M., and Del Rio, C. (1999). Conservation des ressources génétiques de l'Olivier. Paper presented at Séminaire international sur les innovations scientifiques et leur application en oléiculture et oléotechnie, 10-12 Mars (Florence, Italy).

Cantini, C., Cimato, A., and Graziano, S. (1999). Morphological evaluation of olive germplasm present in Tuscany region. Euphytica 109, 173-181 https://doi.org/10.1023/A:1003728800464.

Dominguez-Garcia, M.C., Laib, M., De La Rosa, R., and Belaj, A. (2012). Characterization and identification of olive cultivars from Northeastern Algeria using molecular markers. J. Hortic. Sci. Biotechnol. 87(2), 95-100. https://doi.org/10.1080/14620316.2012.11512837.

Dridi, J., Fendri, M., Breton, C.M., and Msallem, M. (2018). Characterization of olive progenies derived from a Tunisian breeding program by morphological traits and SSR markers. Sci. Hortic. 236 127-136. https://doi.org/10.1016/j.scienta.2018.03.042.

El Bakkali, A., Essalouh, L., Tollo, C., Rivallan, R., Mournet, P., Moukhli, A., et al. (2019). Characterization of worldwide olive germplasm banks of Marrakech (Morocco) and Córdoba (Spain): Towards management and use of olive germplasm in breeding programs. PLoS ONE 14(10): e0223716. https://doi.org/10.1371/journal. pone.0223716.

Emmanouilidou, M.G., and Kyriacou, M.C. (2018). Characterization and identification of indigenous olive germplasm from Cyprus using morphological and simple sequence repeat markers. HortScience 53(9), 1306-1313. https://doi.org/10.21273/HORTSCI13192-18.

FAO (2010). The Second Report on the State of the World's Plant Genetic Resources for Food and Agriculture (Rome, Italy).
FAOSTAT (2017). Agricultural Statistics, Olives. http://www.fao.org/ faostat/fr/.

Giuffrè, A.M. (2017). Biometric evaluation of twelve olive cultivars under rainfed conditions in the region of Calabria, South Italy. Emir J. Food Agric. 29(9), 696-709. https://doi.org/10.9755/ejfa.2017. v29.i9.110.

Green, P.S. (2002). A revision of Olea L. (Oleaceae). Kew Bull. 57, 91-140. https://doi.org/10.2307/4110824.

Haddad, B., Silvestre Gristina, A., Mercati, F., Saadi, A., Aiter, N., Martorana, A., Sharaf, A., and Carimi, F., (2020). Molecular analysis of the official Algerian olive collection highlighted a hotspot of biodiversity in the central Mediterranean basin. Genes 11, 303. https://doi.org/10.3390/genes11030303.

Hadiddou, A., Oukabli, A., Moudaffar, C., Mamouni, A., Gaboun, F Mekaoui, A., H'ssaini, L., and El Fechtali, M. (2013). Evaluation des performances de production de14 variétés d'olivier (Olea europaea L.) nationales et méditerranéennes dans deux systèmes contrastés de culture (pluvial et irrigué) au Maroc. Al Awamia 127, 21-43.

Hamdi, N., and Khanouche, R. (2007). Création de collections d'olivier et de figuier et leur importance dans le développement rural durable. Recherche Agronomique 19, 14-20.

Hannachi, H., Breton, C., Msallem, M., Ben El Hadj, S., El Gazzah, M., and Bervillé, A. (2008). Are olive cultivars distinguishable from oleaster trees based on morphology of drupes and pits, oil composition and microsatellite polymorphisms? Acta Bot. Gallica 155(4), 531-545. https://doi.org/10.1080/12538078.2008.10516132.

Hannachi, H., Martín-Gómez, J.J., Saadaoui, E., and Cervantes, E. (2017). Stone diversity in wild and cultivated olive trees (Olea europaea L.). Dendrobiology 77, 19-32. https://doi.org/10.12657/ denbio.077.002.

Hauville, A. (1953). La répartition des variétés d'olivier en Algérie et ses conséquences pratiques. Bull. Soc. Agricole d'Algérie 580, 1-8.

Idrissi, A., and Ouazzani N. (2006). Apport des descripteurs morphologiques à l'inventaire et à l'identification des variétés d'olivier (Olea europaea L.). Bull. Ress. Phytogénétiques 136, 1-10.

IOC. (1997). Méthodologie pour la caractérisation primaire des variétés d'Olivier. Projet RESGEN-CT(67/97), Union Européenne/ COI. http://www.internationaloliveoil.org/.

IOC. (2018). World production of olives and olive oil. http://www. internationaloliveoil.org/.

Laaribi, I., Gouta, H., and Mezghani Ayachi, M. (2017). Combination of morphological and molecular markers for the characterization of ancient native olive accessions in Central-Eastern Tunisia. C. R. Biologies 340(5), 287-297. https://doi.org/10.1016/j. crvi.2017.03.003

MARDF. (2017). Agricultural statistics of the Ministry of Agriculture and Rural Development and Fisheries, Serie B (Crop production) (Algiers, Algeria: Pub. MARDF).

Mendil, M., and Sebai, A. (2006). Catalogue des Variétés Algériennes de l'Olivier (Algiers: ITAFV Editions).

Pontikis, C.A., Loukas, M., and Kousounis, G. (1980). The use of biochemical markers to distinguish Olive cultivars. J. Hortic. Sci. 55, 333-343. https://doi.org/10.1080/00221589.1980.11514942.

Trujillo, I., Ojeda, A.M., Urdiroz, M.N., Potter, D., Barranco, D., Rallo, L., and Diez, M.C. (2014). Identification of the worldwide olive germplasm bank of Córdoba (Spain) using SSR and morphological markers. Tree Genet. Genomes 10, 141-155. https://doi. org/10.1007/s11295-013-0671-3. 
Received: Oct. 22, 2019

Accepted: Oct. 14, 2020

Addresses of authors:

K. Titouh ${ }^{1, *}$, F. Bradaï ${ }^{2}$, A. Allam ${ }^{3}$, H. Madani ${ }^{3}$, B. Taleb ${ }^{2}$ and M.Z. Aït Meziane ${ }^{4}$

${ }^{1}$ National Institute of Agronomic Research of Algeria (INRAA), Center of Baraki, Algiers, Algeria

${ }^{2}$ University Center Morsli Abdallah of Tipaza, Algeria

${ }^{3}$ National Institute of Agronomic Research of Algeria

(INRAA), Sidi Mahdi Station, Touggourt-Ouargla, Algeria

${ }^{4}$ National Institute of Agronomic Research of Algeria

(INRAA), Oued Ghir Station, Béjaïa, Algeria

* Corresponding author;

E-mail: titouhkheireddine@gmail.com

Tel.: +213667115625; Fax: +21323828563 